\title{
Eosinophilic Dermatosis of Hematologic Disease: A Case Report
}

\author{
Najat Elaattoul ${ }^{1 *}$, Ayman Ismail ${ }^{2}$, Anas Fakhri ${ }^{2}$, Hanane Rais ${ }^{2}$, Ouafa Hocar ${ }^{1}$, Said Amal ${ }^{1}$
}

\author{
${ }^{1}$ Dermatology and Venereology Department of Mohammed VI University Hospital Center, Marrakesh, Morocco \\ ${ }^{2}$ Anatomic Pathology Department of Mohammed VI University Hospital Center, Marrakesh, Morocco
}

DOI: $10.36347 /$ sjmcr.2021.v09i03.033

| Received: 05.03.2021 | Accepted: 22.03.2021 | Published: 30.03.2021

*Corresponding author: Najat Elaattoul

Abstract

Eosinophilic dermatosis of hematologic disease $(\mathrm{EDH})$ or insect bite-like reaction is a rare paraneoplastic manifestation mostly described in patients with chronic lymphocytic leukemia. We report a case of a 67-years-old female patient presented to our dermatology department with a recurrent itchy papulo-vesicular lesions located on her face and extremities accompanied with asthenia and weight loss revealing chronic lymphocytic leukaemia. Based on clinical history and histopathologic features, we concluded to the diagnosis of EDH, and the patient received topical corticosteroids and antihistamines in association to chemotherapy achieving an hematological remission. However, the skin lesions recurred. The interest of this report lies in the rarity of this entity and the difficulty of differential diagnosis with lympho-proliferations. In addition, we aim to stress the fact that EDH can reveal the diagnosis of the hematologic malignancy.

Keywords: Eosinophilic dermatosis of hematologic disease; insect bite-like reaction; chronic lymphocytic leukemia; cutaneous lesions, paraneoplastic manifestation.

Copyright $\odot 2021$ The Author(s): This is an open-access article distributed under the terms of the Creative Commons Attribution 4.0 International License (CC BY-NC 4.0) which permits unrestricted use, distribution, and reproduction in any medium for non-commercial use provided the original author and source are credited.

\section{INTRODUCTION}

Eosinophilic dermatosis of hematologic disease $(\mathrm{EDH})$ or insect bite-like reaction is a rare paraneoplastic manifestation, presenting as a polymorphic pruritic dermatitis, mostly described in patients with chronic lymphocytic leukemia (CLL) [1]. It was first reported by Weed in 1965 as an exaggerated reaction to a mosquito bite $[2,3]$. We report here a case of this disorder revealing the diagnosis of CLL

\section{Case Report}

A 67-years-old female patient presented to our dermatology department with the chief complaint of itchy erythematous papulo-vesicular lesions located on her face and extremities evolving since one month. It was stated that an erythematous rash appeared two months ago accompanied with asthenia and weight loss. No history of insect bites or medication was found.

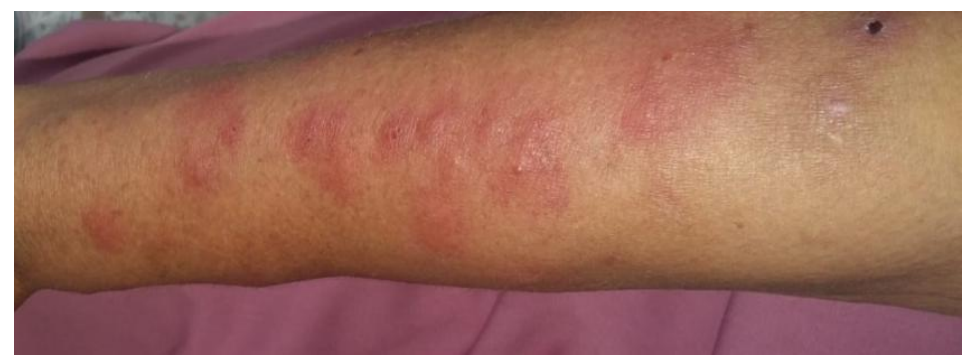

Fig-1: Right forearm photography showing multiple erythematous papules with vesicles at the center

Besides the skin eruption, physical examination showed bilateral cervical and inguinal centrimetric lymphadenopathies and splenomegaly.

The laboratory examination revealed an hyperlymphocytosis at $73370 / \mathrm{mm} 3$. The blood smear and the blood immunophenotyping concluded to the diagnosis of CLL.

The skin biopsy, performed on two sites, displayed a dense lymphocytic perivascular inflammatory infiltration rich with eosinophilic cells. 
The immunohistochemical (IHC) staining results were as follows: strong CD3, CD4 staining and negative CD20 and CD30 staining. Direct immunofluorescence (DIF) was negative.

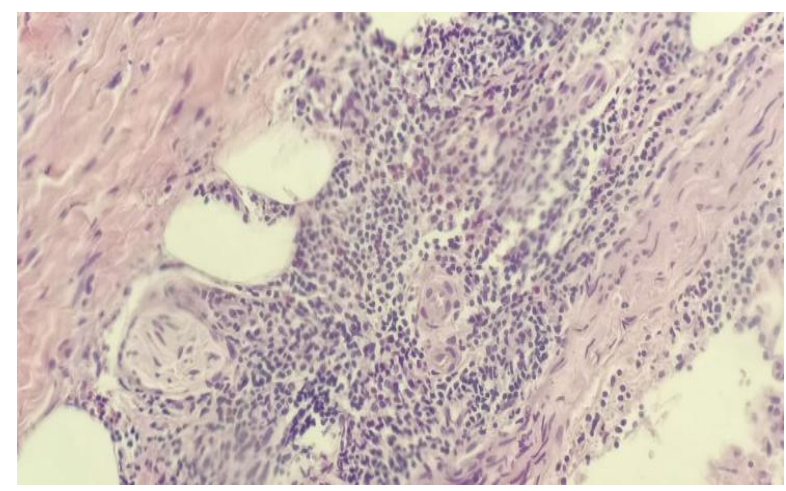

Fig-2: At the skin biopsy, histological study displayed a dense lymphocytic perivascular inflammatory infiltration rich with eosinophilic cells

In view of the suggestive anatomo-clinical aspect, the discovery of CLL and the exclusion of other causes of dermal infiltration by eosinophils, we could conclude to an eosinophilic dermatosis associated with hemopathy (EDH) accompanying a CLL. We prescribed topical corticosteroids and antihistamines. The patient received Chemotherapy using R-CHOP protocol including cyclophosphamide, vincristine, doxorubicin, prednisolone and rituximab, achieving an hematological remission.

A follow-up examination showed the normalization of lymhocytosis. However, the skin lesions recurred intermittently during six months. The one year follow up found skin lesions without hematological relapse.

\section{DiscUSSION}

Eosinophilic dermatosis of hematologic disease is a rare condition. It is probably underdiagnosed because it is often seen as a reaction to real insect bites. EDH has been described in association with hematological malignancies in particular with chronic lymphatic leukaemia (CLL), but also mantlecell lymphoma, natural killer-cell leukaemia/lymphoma, non-Hodgkin lymphoma, acute lymphoblastic or myeloblastic leukemia [2, 4].

The pathogenesis is not fully understood [2]. Some medical authors theorize an extravasation of tumor B cells with skin-homing properties associated with a secondary, predominant, T-cell immune reaction which could explain the clinico-pathological aspect and the prolonged regressive and recurrent course of the disease [4].

Clinical presentation consisted of recurrent itchy erythematous papules, nodules, plaques, and vesicles, predominantly affecting the upper and lower extremities [2]. These aspects are suggestive of insect bites, but the multiple recurrences, the localization on the covered area and the ineffectiveness of symptomatic treatments did not plead in favor of a causal link [4]. The eruption usually appears after the diagnosis of hematologic diseases, but may occur well before or coincide with its diagnosis $[1,5]$.

Histology reveals a sub-epidermal edema formation and dense dermal inflammatory infiltrate. The infiltrate is predominantly composed by lymphocytes, histiocytes and eosinophils. At the immuno-histochemical study, the majority of the infiltrating lymphocytes are CD3+, CD5+ and CD43+, more CD4+ than $\mathrm{CD} 8+$, and only a small minority is CD20+. Eosinophilic spongiosis, intra- or subepidermal bullous lesions, vasculitis lesions or eosinophilic panniculitis are inconstant. The DIF test is negative [4].

The most efficient treatment of this dermatosis appears to be specific chemotherapy for the blood dyscrasia [4].

Various treatments were proposed for skin lesions, however, topical corticosteroids and antihistamines remains generally not very effective, and antibiotics are without significant improvement [2]. Treatments with UVB or PUVA therapy can be useful. Although some studies have also reported positive responses with Dapsone [6]. According to literature findings, the treatment that seems to give the best results is systemic prednisolone at $40 \mathrm{mg}$ daily [2] usually carried out for 15 days.

Some patients report favorable responses to therapy, but the majority relapses or has an incomplete response. Whether insect-bite-like reaction has prognostic implications for patients with CLL remains unclear [7]. Robak and Robak concluded that the prognosis of CLL is unaffected by specific skin infiltrates [8], while Bairey et al noted that a significantly high percentage of patients with cutaneous lesions had an adverse prognosis of CLL [7].

\section{Conclusion}

$\mathrm{EDH}$ is a rare non-specific manifestation of hematologic malignancies. Currently, the diagnosis is based on well-established criteria. The eruption recurrences are frequent and often announce the hematologic disease relapse. As shown in our case, $\mathrm{EDH}$ can reveal the hematologic disease; therefore, clinicians should be aware of this clinical entity as it can also indicate the progression of the underlying disease.

\section{REFERENCES}

1. Carlesimo M, Narcisi A, Orsini D, Abruzzese C, Di Russo PP, La Verde G, Cox MC. Eosinophilic 
dermatosis associated with haematological malignancies: A report of two cases. European Journal of Inflammation. 2012 Aug;10(2):247-50.

2. Ma CM, Chen WC, Shen JL. Insect bite-like reaction in a patient with chronic lymphocytic leukemia. Dermatologica Sinica. 2016;35(3).

3. Weed RI. Exaggerated delayed hypersensitivity to mosquito bites in chronic lymphocytic leukemia. Blood. 1965;26:257-268.

4. Chassine AF, Dadban A, Charfi S, Chaby G, Royer B, Damaj G, Chatelain D, Lok C. Dermatose éosinophilique associée aux hémopathies: étude clinique, histopathologique et immunohistochimique de six cas. InAnnales de Dermatologie et de Vénéréologie 2010 Mar 1 (Vol. 137, No. 3, pp. 181-188). Elsevier Masson.

5. Penn L, Ahern I, Mir A, Meehan S. A. Eosinophilic dermatitis malignancy. Dermatology Online Journal. 2015;21(12):10.

6. Jin A, Pousti BT, Savage KT, Mollanazar NK, Lee JB, Hsu S. Eosinophilic dermatosis of hematologic malignancy responding to dupilumab in a patient with chronic lymphocytic leukemia. JAAD case reports. 2019 Sep;5(9):815-817.

7. Bairey O, Goldschmidt N, Ruchlemer R, Tadmor T, Rahimi- Levene N, Yuklea M, Shvidel L, Berrebi A, Polliack A, Herishanu Y, Israeli Chronic Lymphocytic Leukemia Study Group (ICLLSG). Insect- bite- like reaction in patients with chronic lymphocytic leukemia: a study from the I sraeli C hronic L ymphocytic L eukemia S tudy $\mathrm{G}$ roup. European journal of haematology. 2012 Dec;89(6):491-496.

8. Robak E, Robak T. Skin lesions in chronic lymphocytic leukemia. Leuk Lymphoma. 2007;48(5):855-865. 